Risk spillovers in international equity portfolios

Matteo Bonato, Massimiliano Caporin and Angelo Ranaldo

$\stackrel{m}{\stackrel{n}{\sim}}$

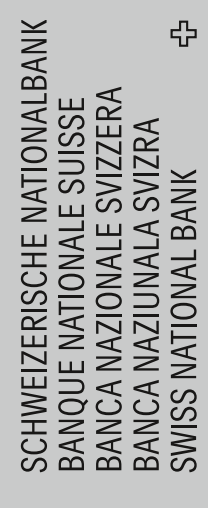

舀岳这变

要专热

(1)

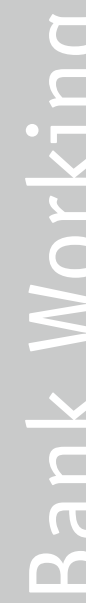


The views expressed in this paper are those of the author(s) and do not necessarily represent those of the Swiss National Bank. Working Papers describe research in progress. Their aim is to elicit comments and to further debate.

\section{Copyright $\odot$}

The Swiss National Bank (SNB) respects all third-party rights, in particular rights relating to works protected by copyright (information or data, wordings and depictions, to the extent that these are of an individual character). SNB publications containing a reference to a copyright ( $\odot$ Swiss National Bank/SNB, Zurich/year, or similar) may, under copyright law, only be used (reproduced, used via the internet, etc.) for non-commercial purposes and provided that the source is mentioned. Their use for commercial purposes is only permitted with the prior express consent of the SNB.

General information and data published without reference to a copyright may be used without mentioning the source.

To the extent that the information and data clearly derive from outside sources, the users of such information and data are obliged to respect any existing copyrights and to obtain the right of use from the relevant outside source themselves.

\section{Limitation of liability}

The SNB accepts no responsibility for any information it provides. Under no circumstances will it accept any liability for losses or damage which may result from the use of such information. This limitation of liability applies, in particular, to the topicality, accuracy, validity and availability of the information.

ISSN 1660-7716 (printed version)

ISSN 1660-7724 (online version)

๑ 2012 by Swiss National Bank, Börsenstrasse 15, P.0. Box, CH-8022 Zurich 


\title{
Risk spillovers in international equity portfolios
}

\author{
Matteo Bonato* Massimiliano Caporin ${ }^{\dagger}$ Angelo Ranaldo ${ }^{\ddagger}$ \\ Current Draft: February 2012
}

\begin{abstract}
We define risk spillover as the dependence of a given asset variance on the past covariances and variances of other assets. Building on this idea, we propose the use of a highly flexible and tractable model to forecast the volatility of an international equity portfolio. According to the risk management strategy proposed, portfolio risk is seen as a specific combination of daily realized variances and covariances extracted from a high frequency dataset, which includes equities and currencies. In this framework, we focus on the risk spillovers across equities within the same sector (sector spillover), and from currencies to international equities (currency spillover). We compare these specific risk spillovers to a more general framework (full spillover) whereby we allow for lagged dependence across all variances and covariances. The forecasting analysis shows that considering only sector- and currency-risk spillovers, rather than full spillovers, improves performance, both in economic and statistical terms.
\end{abstract}

JEL classification: C13, C16, C22, C51, C53, G17.

Keywords: Risk spillover; portfolio risk; currency risk; variance forecasting; international portfolio; Wishart distribution.

\footnotetext{
${ }^{*}$ Matteo Bonato is a quantitative risk analyst in the Independent Verification Unit at UBS AG, Zurich, Switzerland. (E-mail: matteo.bonato@ubs.com.)

${ }^{\dagger}$ Massimiliano Caporin is Associate Professor of Econometrics at the Department of Economics "Marco Fanno", University of Padua, Padua, Italy (E-mail: massimiliano.caporin@unipd.it).

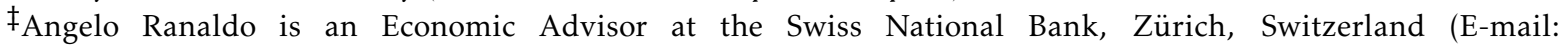
ranaldo@bluewin.ch).

Massimiliano Caporin gratefully acknowledges financial support from the University of Padova research project CPDA073598.

We would like to thank Jan Wrampelmeyer for his useful comments and suggestions.

- The views expressed herein are those of the authors and do not necessarily reflect those of the Swiss National Bank or of UBS AG, which neither of these entities accept any responsibility for the content and opinions expressed in this paper.
} 


\section{Introduction}

How can we define risk spillovers? How can we model risk spillovers in an international equity portfolio? If we take risk spillover into account, does the forecasting ability of portfolio risk increase? What are the economic consequences of only limited risk spillovers? In this paper, we address these fundamental questions.

In order to characterize the risk relations across assets, we assume that the asset covariance matrix is dynamic and we characterize the dependence across its elements. Then, we introduce the concept of risk spillover which defines the dependence of a given asset variance on the past covariances and variances of assets that either belong to the same or different economic sectors or asset classes. When the dependence encompasses all assets included in a portfolio, we refer to it as full risk spillover. At the other extreme, there is an absence of risk spillover, i.e. when the risk of any asset is a function only of its past risk. There is a vast spectrum of partial risk spillover between none and full spillover risk. To envisage these, we assume the point of view of a U.S. investor holding an international equity portfolio of nine U.S. stocks and three foreign stocks. The underlying twelve companies run their business in four sectors. The investor is essentially concerned by two kinds of risk spillovers: first, the currency-risk spillover, which arises from the foreign companies that perform business predominately abroad and/or use foreign accounting currencies. Second, the sector-risk spillover that stems from companies with the common exposure to sector-wide risk factors. More specifically, we focus on three structures of partial risk spillover in the variance-covariance matrix. First, we consider what we call "limited-risk spillover", that is to say, the interaction of risks within economic sectors and between the three exchange rates (we consider currencies as an asset class per se). It should be stressed that this definition of partial risk spillover discards any risk spillover across economic sectors and between equities and currencies. Second, we consider the "currency-risk spillover", in which the risk spillover is given by the currency risk, and only impacts international equities. Finally, we discuss the "pervasive-risk spillover" that combines the limited- and currency-risk spillovers mentioned above. This corresponds to the joint presence of risk spillover between currencies, within equities in the same economic sector, and from currencies to international equities.

Building on the concept of risk spillover, we propose a flexible and feasible approach to 
model equity portfolio risk which involves exchange rate risks. This model lends itself to adaptable definitions of risk and various structures of risk forecasting. It is worth noticing that one could consider many other definitions of partial-risk spillover (e.g. the cross-sector risk spillover) and other asset classes (e.g. government or corporate bonds). We limit our analysis to an international equity portfolio, based on our firm belief that this approach can easily be extended to encompass many other interactions between asset variances/covariances and how these relations evolve over time. Though this is not within the scope of this paper, such a portfolio design can be used to study to the efficient hedging of currency risks.

One of the benefits of efficient hedging in an international exposure is the reduction of the portfolio variance, see for example Glen and Jorion (1993). In addition, as shown in Campbell et al. (2010), risk-minimizing global equity investors should short those currencies that are more positively correlated with equity returns and should hold long positions in those currencies that are more negatively correlated with returns. Our paper contributes to this strand of the literature by proposing a modeling approach to spillover risk and challenging the view that some currencies have diversification benefits. In fact, by opportunely modeling spillover risks, the economic assessment of these diversification benefits become less clear.

This approach is consistent with the variety of investment funds in the financial industry and makes a broad spectrum of risk management strategies viable. For instance, the investor can believe ex ante that an asset class, such as hedge fund investments, should by its very nature be poorly correlated with other (traditional) securities, such as stocks and bonds. Another example is represented by the unclear connection between currencies and equities, or even among sectors that may be pro-cyclical (e.g. manufacturing and resources) or counter-cyclical (e.g. pharmaceutical and health sectors). Those alternative spillover designs might be easily obtained as generalizations or sub-cases of our modelling approach.

From the technical side, our study relies on the Wishart autoregressive model (WAR) proposed by Gourieroux et al. (2009). The model is based on a dynamic extension of the Wishart distribution. This specification is compatible with financial theory, satisfies the constraints on volatility matrices, has a flexible form and, most importantly, maintains the coefficients' interpretability, even when specifications are restricted. The main innovation proposed in this paper is the introduction of specific model parametrizations that allows the dynamics of the spillover between variances to be controlled by imposing a particular structure on the coefficient matrices 
of the WAR model. The parametrization makes use of block structures on the model parameter matrices. We hence name our specification Block WAR. The use of block structures in parameter matrices is similar to that adopted in Billio et al. (2006), Billio and Caporin (2008), and Engle and Kelly (2008) that introduce a block structure for the correlation matrix. Similar approaches have been considered in Asai et al. (2008) for multivariate stochastic volatility models. Finally, Caporin and Paruolo (2008) present a more general spatial solution to the curse of dimensionality problem in multivariate volatility specifications. Their specification includes as a special case block structures on the coefficient matrices.

After the model estimation, we perform a forecasting analysis to evaluate the economic implications which stem from different characterizations of the risk spillover. The forecasting ability of several alternative model specifications is assessed both in statistical and economic terms. On the economic side, the crucial mechanism is that the optimized portfolio weights and the variance forecasts depend on how spillovers are structurally modelled. Consistent with the recent literature on realized volatility, the empirical analysis is based on high frequency data of 12 stocks quoted on US equity markets and 3 exchange rates over a period of seven years, including those of the recent financial crisis.

The paper is organized as follows: Section 2 introduces the econometric model used to analyze and forecast the sequence of covariance matrices while accounting for possible spillover effects. Section 3 describes the model estimation procedure; Data and model specification are presented in Section 4; the economic value of considering risk spillover is analyzed in Section 5. Section 6 concludes the paper.

\section{Modeling variance spillovers}

We now introduce the model used to analyze and forecast the sequence of realized variancecovariance matrix for the 15 assets in our study. Later, we describe the set of alternative parametric restrictions to the spillovers between variances that help to reduce the complexity of the full model estimation, and those which might be driven by some economic criterion (e.g. assets classification) or data. As we mention in the introduction, we presume that realized covariance sequences are available and so will not tackle the problem of the optimal estimation of realized variances and covariances. Details on these aspects could be found in Zhang et al. (2005), 
Bandi and Russel (2008), Hansen and Lunde (2006) , Barndorff-Nielsen et al. (2008a) and Zhang (2010), among others.

\subsection{The Wishart autoregressive process}

Once we have computed the series of realized variance/covariance matrices from the intra-day returns, it is of fundamental importance, for our purpose, to adopt a model which: can be estimated even with a large set of assets; that guarantees the positive definitiveness of the forecasted covariance matrix; and whose coefficients keep their interpretability. This last aspect is even more important if the quality of covariance matrix forecasts is measured according to an economic criterion (such as the returns on various optimized portfolios).

A model that satisfies the previously itemized requirement is the realized Wishart autoregressive model (WAR) of Gourieroux et al. (2009). We will not formally introduce the WAR model, neither we will present its properties; interested readers might refer to the cited paper. As shown in Bonato et al. (2008), this model is particularly suitable for testing the variance spillover between assets. In their paper, the authors propose four specifications to restrict the interaction between past variances/covariances with their contemporaneous values.

Denote by $Y_{t}$ the time $t$ (realized) covariance for a group of $n$ assets. If the sequence of stochastic positive definite $Y_{t}$ matrices follows a Wishart process, the expected value of $Y_{t+1}$, conditioned on the information up to time $t$, is given by:

$$
E_{t}\left(Y_{t+1}\right)=M Y_{t} M^{\prime}+K \Sigma
$$

In that case, we say that $Y_{t}$ is a Wishart autoregressive process of order 1, WAR(1), denoted $W[K, M, \Sigma]$. The density of the WAR(1) process depends on the following parameters: $K$, the scalar degree of freedom strictly greater than $n-1$ (the dimension of $Y_{t}$ - the number of assets - minus one); $M$, the $n \times n$ matrix of autoregressive parameters; and $\sum$, the $n \times n$ symmetric and positive definite matrix of innovation covariances. An important property of the Wishart distribution is that the matrices $Y_{t}$ are positively definite if and only if $K \geq n^{1}$. See Gourieroux et al. (2009) for additional details on the derivation of the WAR process.

\footnotetext{
${ }^{1}$ Furthermore, for a non-centered Wishart specification, the distribution of $Y_{t}$ possesses a density function only when $K>n-1$ (hence the condition above). Thus, for $K<n-1$ no density can be defined and for $K<n$ the process $Y_{t}$ is given by a sequence of singular covariance matrices with degenerate Wishart distribution (Muirhead, 1982).
} 


\subsection{Interpretation of the coefficients}

Let us consider the simple setting in which we are given an even number of assets $n$ which we can cluster into two groups of size $n / 2$. Under the assumption that the autoregressive matrix $M$ is block diagonal, with $M_{11}$ and $M_{22}$ being $n / 2 \times n / 2$ matrices, it is straightforward to show that

$$
\left(\begin{array}{ll}
M_{11} & \\
& M_{22}
\end{array}\right)\left(\begin{array}{ll}
Y_{11, t} & Y_{12, t} \\
Y_{21, t} & Y_{22, t}
\end{array}\right)\left(\begin{array}{ll}
M_{11}^{\prime} & \\
& M_{22}^{\prime}
\end{array}\right)=\left(\begin{array}{ll}
M_{11} Y_{11, t} M_{11}^{\prime} & M_{11} Y_{12, t} M_{22}^{\prime} \\
M_{22} Y_{21, t} M_{11}^{\prime} & M_{22} Y_{22, t} M_{22}^{\prime}
\end{array}\right),
$$

which gives the expression for $E_{t}\left[Y_{t+1}\right]$ with the quantity $K \sum$ to be added. We see that constraining $M$ to be a block diagonal matrix has the effect of limiting co-volatility spillover effects between different groups. Only past variance-covariance values of group 1 influence future values of group 1. The same holds for group 2 as well as for the between-group covariances.

In order to analyze the spillover effect within groups in greater details, we consider the following $(2 \times 2)$ matrices: the covariance matrix $Y_{t}$; the autoregressive parameter matrix $M$; and the innovation variance $\Sigma$. The matrices have the following structure:

$$
Y_{t}=\left(\begin{array}{ll}
Y_{11, t} & Y_{12, t} \\
Y_{12, t} & Y_{22, t}
\end{array}\right), M=\left(\begin{array}{ll}
m_{11} & m_{12} \\
m_{21} & m_{22}
\end{array}\right) \quad \text { and } \quad \sum=\left(\begin{array}{cc}
\sigma_{11} & \sigma_{12} \\
\sigma_{12} & \sigma_{22}
\end{array}\right)
$$

The full WAR(1) model specifies the best prediction of $Y_{t}, E_{t-1}\left[Y_{t}\right]$, as:

$$
E_{t-1}\left[Y_{t}\right]=\left(\begin{array}{cc}
a_{1} Y_{11, t-1}+b_{1} Y_{12, t-1}+c_{1} Y_{22, t-1}+d_{1} & a_{2} Y_{11, t-1}+b_{2} Y_{12, t-1}+c_{2} Y_{22, t-1}+d_{2} \\
- & a_{3} Y_{11, t-1}+b_{3} Y_{12, t-1}+c_{3} Y_{22, t-1}+d_{3}
\end{array}\right)
$$

where $a_{j}, b_{j}, c_{j}$ and $d_{j}, j=1, \ldots, 3$ are scalar parameters, and $d_{j}$ is equal to $K$ multiplied the corresponding entries of $\Sigma$. By construction, the prediction is a symmetric semi-definite positive matrix for any $Y_{t-1}$ which belongs to $\mathcal{S}^{+}$, the set of symmetric positive definite matrices. $\mathrm{Pa}$ rameters in the prediction $E_{t-1}\left[Y_{t}\right]$ might be represented in terms of the parameters in $M$ as follows:

$$
\left\{\begin{array}{ccc}
a_{1}=m_{11}^{2}, & b_{1}=2 m_{11} m_{12}, & c_{1}=m_{12}^{2}, \\
a_{2}=m_{11} m_{21}, & b_{2}=m_{11} m_{22}+m_{21} m_{12}, & c_{2}=m_{12} m_{22}, \\
a_{3}=m_{21}^{2}, & b_{3}=2 m_{21} m_{22}, & c_{3}=m_{22}^{2},
\end{array}\right.
$$

The effect of the past variances and covariances on the present volatility clearly emerges. First, note that the full WAR model allows for spillover between variances and covariances. However, setting $m_{12}=0$ implies that the conditional variance of the first asset depends only on 
its past shocks and that the second asset variance does not influence the conditional covariance. Furthermore, a diagonal specification of $M$ corresponds to the absence of spillovers between variances and covariances, since all elements of $E_{t-1}\left[Y_{t}\right]$ are only functions of the corresponding element of $Y_{t-1}$.

In fact, when $M$ is diagonal, i.e. when $m_{12}=m_{21}=0$, we have:

$$
\begin{aligned}
& E_{t}\left[Y_{11 \mid t+1}\right]=m_{11}^{2} Y_{11, t}+K \sigma_{11}, \\
& E_{t}\left[Y_{12 \mid t+1}\right]=m_{11} m_{22} Y_{12, t}+K \sigma_{12}, \\
& E_{t}\left[Y_{22 \mid t+1}\right]=m_{22}^{2} Y_{22, t}+K \sigma_{22} .
\end{aligned}
$$

This very simple two-dimensional example helps us to identify the coefficients in $M$ that play a role in the spillover effect between variances and covariances. We will now present four different parametrizations for the WAR process that impose limited spillover or that totally exclude spillovers across variances and covariances.

\subsection{WAR specifications for risk spillover modelling}

To derive the WAR specifications needed to model risk spillover, we impose a set of restrictions on the matrix $M$. These restrictions come from a criterion based on asset groups. Such a requirement is economically valid and some examples are given by grouping rules based on the economic sectors to which the stocks entering an equity portfolio pertain, on the type of assets which enter a diversified portfolio, or on the geographical reference areas. The main intuition behind asset grouping is that the clustered variables may share common patterns or common risk factors. In fact, we can presume that assets in the same economic sector may react in a similar way to sector-wide or market-wide shocks/news, and are similarly affected by market movements.

Clearly, groups may be defined on a data-driven basis, referring to factors such as the dynamic properties of the series mean and/or variances, or on a variety of mixed criteria. The comparison of alternative methods of clustering financial assets is beyond the scope of this paper and will not be considered. Some examples are given in Bauwens and Rombouts (2007), and Aielli and Caporin (2011). In the following step, we will use a priori defined groups of stocks (grouped by sectors or cyclicality) and cluster the exchange rates is a separate group. 
In a very general case, we assume that our portfolio consists of $n$ stocks and currencies and that we can classify them into $N$ groups, according to some criterion. The $N$ groups have dimension $n_{i}$ with $\sum_{i} n_{i}=n$. In addition, the assets are ordered according to a group rule, that is, assets from 1 to $n_{1}$ belong to group 1 , assets from $n_{1}+1$ to $n_{1}+n_{2}$ belong to group 2, and so on. Given this asset classification, the autoregressive matrix M may be partitioned as follows:

$$
M=\left(\begin{array}{ccc}
M_{11} & \cdots & M_{1 N} \\
\vdots & M_{i i} & \vdots \\
\vdots & \vdots & M_{N-1, N} \\
M_{N 1} & \cdots & M_{N N}
\end{array}\right),
$$

where $M_{i j}$ is a matrix of dimension $n_{i} \times n_{j}$.

By imposing a particular structure on the matrices $M_{i j}$ we are able to control for the spillover of volatility between and within groups. The basic assumption we are making is that spillover effects are not present between assets belonging to different groups. Therefore, $M$ is a block diagonal matrix with zero off-diagonal elements: $M_{i, j}=\mathbf{0}, \forall i \neq j$. The structure considered for the diagonal blocks $M_{i i}$ will be of two types:

(1) $M_{i i}$ is full

(2) $M_{i i}$ is diagonal.

Specification (1) implies that there are risk spillover effects in terms of variances/covariances within assets belonging to the same economic sector. We refer to that as "limited-risk spillover" to differentiate it from the more general case of "full-risk spillover" associated with a full matrix M. Specification (2) considers the case in which there is no risk spillover effect at all, even within groups. In this case we have the absence of risk spillover and we refer to "no risk spillover". This means that the dynamics of future variances / covariances are solely a function of their past values. Both approaches can be further restricted by imposing unique scalar values for all the entries in $M_{i, i}$. Thus, within each group, a single parameter regulates the effect of past co-volatilities on their future values.

Throughout the empirical we will assume $M$ to be block diagonal while keeping the full $M$ as a benchmark. Then, we will evaluate the implications of the proposed restrictions in terms of risk forecasting. 
The full M matrix implies the existence of risk spillovers across all assets. Note that the general case of a full M quickly becomes computationally infeasible when the number of assets is large, as M contains $n^{2}$ distinct coefficients. Therefore, it should be perceived as a generic and optimal benchmark to be taken as a reference for restricted specifications, which exclude certain kinds of risk spillovers. The full risk spillover and the no risk spillover cases would permit an evaluation of the benefits of including of risk spillovers in the model.

Besides the use of diagonal or block-diagonal specifications for matrix $\mathrm{M}$, an interesting alternative design points at the role of the sub-matrix $M_{N-1, N}$, a single off-diagonal block, which might be added to a block-diagonally specified M matrix. Assume, for ease of exposition, that we are interested in evaluating the volatility spillovers between assets belonging to groups $N-1$ (international equities) and $N$ (currencies). The most natural way of accomplishing this would be to consider them as a unique sector and to consider the lower left diagonal block of $M$ of size $n_{N-1}+n_{N}$. The drawback of this specification is that spillover effects are bi-directional, i.e. assets in group $N-1$ influence group $N$ and vice versa. This may not be an appropriate choice as it implicitly assumes that currency volatilities (group $N$ ) are affected by these equity volatilities (group $N-1$ ). Simple algebra shows that to consider the equities in $N-1$ and the currencies in $N$ as a separate group, and and set $M_{N, N-1}$ to zero solves this issue. As a result, currency-risk will be present in the model and associated with the parameters of $M_{N-1, N}$. In particular, this is included in our empirical analysis on an ad hoc basis if the two groups have the same dimensions, and the parameter matrices $M_{N-1, N-1}, M_{N-1, N}$ and $M_{N, N}$ are diagonal, then the volatility of assets in $N$ influences only the volatility of the assets in $N-1$, which hold the same position within the block. Furthermore, the currency risk spillover effect only exists between variances and is mono-directional from group $N$ to $N-1$.

\section{Estimation}

Here, we follow Gourieroux et al. (2009) and briefly describe how the WAR parameters are estimated. Note that the theoretical results in Gourieroux et al. (2009) directly apply to our restricted WAR parametrizations.

The first-order conditional moments of the WAR can be used to calibrate the parameters in $M$ and $\Sigma$, up to the sign and scale factor, respectively. As the first-order method of moments is 
equivalent to non-linear least squares, the estimator is defined as:

$$
\left(\hat{M}, \hat{\Sigma}^{*}\right)=\operatorname{Argmin}_{M, \Sigma^{*}} S^{2}\left(M, \Sigma^{*}\right)
$$

where:

$$
\begin{aligned}
S^{2}\left(M, \Sigma^{*}\right) & =\sum_{t=2}^{T} \sum_{i<j}\left(Y_{i j, t}-\sum_{k=1}^{n} \sum_{l=1}^{n} Y_{k l, t-1} m_{i k} m_{l k}-\sigma_{i j}^{*}\right)^{2} \\
& =\sum_{t=2}^{T}\left\|\operatorname{vech}\left(Y_{t}\right)-\operatorname{vech}\left(M Y_{t-1} M^{\prime}+\Sigma^{*}\right)\right\|^{2}
\end{aligned}
$$

and $\Sigma^{*}=K \Sigma$.

We follow the strategy proposed in Bonato (2009) to estimate the degrees of freedom. It has been shown to be less sensitive to the presence of extreme events in the co-volatility process. Consider a portfolio allocation $\alpha \in \mathbb{R}^{n}$. We know that the unconditional distribution of $Y_{t}$ is a $W(K, 0, \Sigma(\infty))$, a centered Wishart distribution. We can therefore easily show that:

$$
\alpha^{\prime} Y_{t} \alpha \sim \mathrm{Ga}\left(\frac{K}{2}, 2 \alpha^{\prime} \Sigma(\infty) \alpha\right)
$$

i.e. the distribution of the portfolio with allocation $\alpha$ is a gamma distribution with the degrees of freedom $K$ as shape parameter, (see also Meucci, 2005). An unbiased estimator of $K$ can most probably be simply obtained via maximum likelihood by fitting a gamma distribution into the process $\alpha^{\prime} Y_{t} \alpha$.

\section{Data and model specification}

The dataset consists of 15 assets, 12 stocks and 3 exchange rates. Stock data are provided at a 1minute frequency by Tickdata.com. Exchange rate data are also provided at 1-minute frequency by Disktrading.com. The period we consider spans from January 2, 2003 to December 31, 2009. Table 1 reports the name of the assets used in the analysis along with their sector and cyclicality, the currency of their financial statements and the betas with respect to the S\&P500 Index.

Factoring out weekends, holidays, days with shorter trading hours (e.g. July 3 or December 24) and matching all the days across the sample, we are left with 1,759 trading days. Intraday returns are then computed by taking the log differences of the 1-minute prices and multiplying by $10^{4}$. Daily returns are obtained as the difference of the logarithm of the closing and opening price of the day and multiplying by 100 . Note that we do not consider the effect of overnight 
Table 1: Grouping of the stocks according to their market sector/geographical location. The last column reports the $\beta$ s (for the period under analysis) with respect to the S\&P500 index.

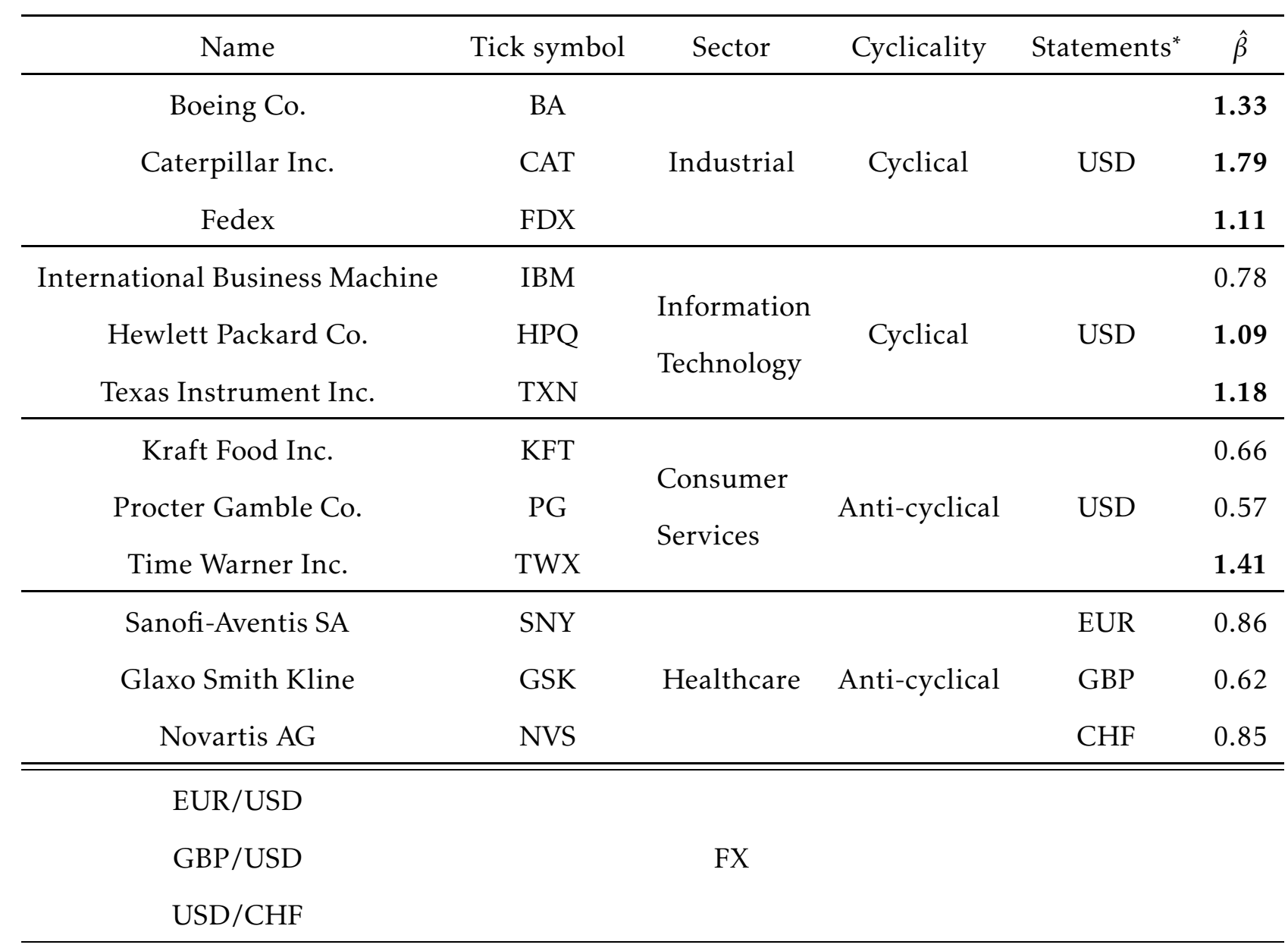

* Statements denotes the currency in which the company releases its financial statements and dividends. 
returns as we assume the representative agent opens and closes his position within the same trading day. This simplifying assumption is motivated by the difficulty involved in considering the overnight effect jointly on currency and stock trading, as forex is virtually traded around the clock and stocks are not. The overlapping trading hours of our portfolio coincide with stocks' trading hours. Table 2 reports the summary statistics for the 1-minute and open-to-close returns on the 15 series.

The goal of the paper is to assess whether there is economic loss, in terms of forecasting power and asset allocation performances, if all possible kinds of risk spillovers in an international equity portfolio are constrained to a limited set of risk transmission. The introduction of restricted parametrizations of the WAR induces computational simplifications, maintains parameter interpretability and allows a clear identification of currency-risk spillovers and sectorrisk spillovers.

The first task of our analysis consists in computing a measure of covariance between the assets making up the portfolio. We accomplish this by following the recent developments in literature and exploiting the availability of high frequency data.

The trading day we construct runs from 9:35 AM (first observation) to 16:00 (last observation). Sampling every 5 minutes, we obtained 77 intraday returns which we used to construct the series of realized covariance matrices.

In the next step we compute the series of realized covariance matrices using the classical estimator presented in Andersen et al. (2003) and Barndorff-Nielsen and Shephard (2004) de Pooter et al. (2006):

$$
Y_{t}=\sum_{i=1}^{I} r_{t-1+i h, h} r_{t-1+i h, h}^{\prime}
$$

With $Y_{t}$ we indicate the realized covariance matrix at time $t$ in order to to be coherent with our previous notation and because the use of $\Sigma$ would probably create confusion as $\Sigma$ denotes the covariance matrix of the Gaussian vector underlying the WAR(1) model. $r_{t-1+i h, h} \equiv$ $p_{t-1+i h}-p_{t-1+(i-1) / h}$ denotes the $(n \times 1)$ vector of returns for the $i$-th intraday period on day $t$, for $i=1, \ldots, I$, and with $n=4$ as the number of assets. I refers to the number of intraday intervals, each of length $h \equiv 1 / I$. In our case, with a frequency of five minutes, $I=76$. One shortcoming of the covariance matrix estimator we adopted is that it is not efficient in the presence of market microstructure noise and asynchronous trading (see for example Sheppard, 2006, Lunde and 
Table 2: Descriptive statistics of the 1-minute and daily (open-to-close) returns over the period January 2, 2003 December 31, 2009. The means are scaled by $10^{4}$, the remaining statistics by $10^{2}$.

\begin{tabular}{ccccccc}
\hline Stock & Mean & Max & Min & SD & Skewness & Kurtosis \\
\hline 1-minute & & & & & & \\
BA & 0.011 & 3.436 & -4.765 & 0.090 & 0.106 & 45.252 \\
CAT & 0.007 & 3.141 & -4.821 & 0.102 & -0.007 & 49.032 \\
FDX & 0.011 & 3.071 & -3.258 & 0.088 & 0.258 & 45.202 \\
IBM & 0.023 & 2.893 & -2.146 & 0.073 & 0.129 & 38.623 \\
HPQ & 0.040 & 6.724 & -11.931 & 0.096 & -2.556 & 420.662 \\
TXN & 0.007 & 5.251 & -4.209 & 0.111 & 0.230 & 55.760 \\
KFT & -0.000 & 4.800 & -10.013 & 0.074 & -3.490 & 610.883 \\
PG & 0.018 & 2.774 & -5.452 & 0.063 & -1.005 & 158.148 \\
TWX & 0.024 & 3.901 & -3.129 & 0.103 & 0.345 & 34.706 \\
SNY & -0.006 & 10.471 & -8.398 & 0.085 & -1.710 & 811.158 \\
GSK & -0.012 & 5.852 & -5.084 & 0.074 & 0.902 & 349.135 \\
NVS & -0.000 & 5.280 & -3.105 & 0.063 & 0.595 & 320.593 \\
\hline EUR & -0.039 & 0.693 & -1.059 & 0.049 & -0.097 & 12.486 \\
GBP & 0.025 & 1.122 & -0.636 & 0.046 & 0.117 & 16.377 \\
CHF & 0.029 & 1.024 & -1.155 & 0.045 & 0.036 & 21.113 \\
\hline \hline Daily O-to-C & & & & & & \\
BA & 0.041 & 7.531 & -8.323 & 1.607 & -0.024 & 5.781 \\
CAT & 0.026 & 10.776 & -8.562 & 1.873 & -0.054 & 6.299 \\
FDX & 0.042 & 8.779 & -9.297 & 1.747 & 0.143 & 6.895 \\
IBM & 0.091 & 5.836 & -6.861 & 1.236 & -0.172 & 6.456 \\
HPQ & 0.155 & 9.804 & -11.170 & 1.715 & -0.059 & 6.900 \\
TXN & 0.028 & 9.663 & -8.599 & 1.970 & 0.053 & 4.828 \\
KFT & -0.001 & 6.467 & -6.517 & 1.284 & 0.050 & 6.589 \\
PG & 0.070 & 7.444 & -6.817 & 1.038 & -0.188 & 9.044 \\
TWX & 0.092 & 11.763 & -11.935 & 1.780 & 0.289 & 9.813 \\
SNY & -0.024 & 12.783 & -8.692 & 1.511 & -0.076 & 9.425 \\
GSK & -0.046 & 6.552 & -8.778 & 1.253 & -0.282 & 8.494 \\
NVS & -0.001 & 6.131 & -5.836 & 1.089 & 0.154 & 6.909 \\
\hline EUR & -0.019 & 2.293 & -2.792 & 0.397 & -0.298 & 8.192 \\
GBP & -0.022 & 1.880 & -2.560 & 0.376 & -0.159 & 7.801 \\
CHF & -0.030 & 1.881 & -2.745 & 0.429 & -0.343 & 6.840 \\
\hline & & & & & & \\
\hline
\end{tabular}


Voev, 2007, Barndorff-Nielsen et al., 2008b, Mancino and Sanfelici, 2008, among others). We think this does not represent an issue here for two reasons. Firstly, we use very liquid assets that are traded in the same markets (CBoT for the futures and OTC for the currencies). This reduces the distortion induced by stale prices, non-homogenous trading times, irregularly spaced data points, asynchronism, different institutional features using different trading platforms or exchange systems. Secondly, as shown in Barndorff-Nielsen et al. (2008b) using the intraday data of 10 stocks from the Dow Jones index, the estimated realized covariance matrices based on 5-minute returns are not significantly biased ${ }^{2}$ (compared to the matrices constructed using the outer products of the open to close returns).

\subsection{Asset classes and portfolio construction}

As discussed in the previous sections, the ability to model risk spillover within or between assets requires that assets be clustered in well-defined classes.

Taking the U.S.'s investor point of view, we consider a hypothetical portfolio of 12 stocks and three exchange rates in the same order as in Table 1 . These 15 assets are then split into three sectors (Industry, Information Technology, Consumer Service and Healthcare) and an additional group of three exchange rates. More specifically, the portfolio is organized as follows:

- U.S. stocks traded at NYSE - company financial statements in USD: BA, CAT, FDX, IBM, HPQ, TXN, KFT, PG and TWX;

- Three European stocks traded at the NYSE as ADR, for which the company's financial statements are denominated in foreign currencies;

- Three exchange rates: EUR, GBP and CHF all against USD.

As regards the U.S. and the non-U.S. stocks, these can be further grouped by sector:

- Industrials - BA, CAT, FDX;

- Information Technology - IBM, HPQ, TXN;

\footnotetext{
${ }^{2}$ For a given estimator, say $Y_{t}=\operatorname{Cov}_{t}^{5 m}$, Barndorff-Nielsen et al. (2008b), consider the difference $d_{t}=\operatorname{Cov}_{t}^{5 m}-$ $\mathrm{Cov}_{t}^{\mathrm{OtoC}}$ where $\mathrm{Cov}_{t}^{\mathrm{OtoC}}$ is the outer product of the open-to-close returns which, when averaged over many days, provide an estimator of the average covariance between asset returns. The sample bias is computed as $\bar{d}$ and the robust variance as $\bar{e}^{2}=\gamma_{0}+2 \sum_{h=1}^{q}\left(1-\frac{h}{q+1}\right) \gamma_{h}$, where $\gamma_{h}=\frac{1}{T-h} \sum_{t=1}^{n-h} \eta_{t} \eta_{t-h}$. Here $\eta_{t}=d_{t}-\bar{d}$ and $q=\operatorname{int}\left\{4(T / 100)^{2 / 9}\right\}$. Under the null hypothesis that there is no difference between the two estimators the one percent level $|\sqrt{T} \bar{d} / \bar{e}|<2.326$ for each entry of $\operatorname{Cov}_{t}^{5 m}$.
} 
- Consumer Service - KFT, TWX, PG;

- Healthcare - SNY, GKS, NVS.

In a first specification we will consider these sectoral combinations of stocks and currencies as the groups which form the portfolio.

Industrials and Information Technology are generally considered to be pro-cyclical whereas Consumer Service and Healtcare are anti-cyclical stocks. The last column in Table 1 shows the $\beta$ s of these assets for the period under analysis calculated with respect to the S\&P 500 index. All but one of the assets labeled as pro-cyclical display a $\beta$ greater than 1 , indicating that these assets are more sensitive to market movements. The opposite characteristic holds for the anti-cyclical assets, with 5 out of $6 \beta$ s being smaller than 1, i.e. these stocks are less exposed to market risk. Therefore, we decided to include a second approach in our analysis: we classify the portfolio components as pro-cyclical, anti-cyclical and currencies.

Beside the equity market-specific risk, our investor is exposed to exchange rate risk as the performance of the ADR stocks is also influenced by adverse exchange-rate movements. To enable this investor to reduce the risk induced by the currency exposure, we assume that his portfolio includes the three exchange rates against the USD of the countries in which the non-U.S. firms are located: UK (Glaxo Smith Kline), France (Sanovis Aventis SA) and Switzerland (Novartis $A G)$. As a result, the investor will hold an internationally diversified portfolio containing equities and currencies. We note that to be long in ADRs implies that the perfect hedging of currency risk for the equity-only portfolio will be obtained with long positions in the currencies when those currencies represent the exchange of USD against the local currency. In order to impose short-selling constraints on our investor and to have the perfect hedge within his allocations universe, the investor must be able to cover his equity positions with positive weights on the currencies. As USD is not the leading currency against EUR and GBP exchange rate, in the empirical analysis we simply take the reciprocal USD/GBP and USD/EUR when building our optimal portfolios. Note that, when currencies are considered as a specific asset class, the perfect hedge is just a special case: it is associated with an equality restriction on portfolio weights of the ARD's and corresponding currencies. We stress that our focus is not the construction of the optimal hedge, but rather to evaluate the impact of currency risk spillover. In our portfolio design currencies represent investable assets and hedging might be obtained as a by-product. 
The question we want to answer is whether considering volatility spillovers between stocks belonging to different groups or within the same group ${ }^{3}$ delivers acceptable out-of-sample forecasts of the realized covariance matrix of the portfolio under analysis. In particular, we are interested in the effect of what we dub currency-risk spillover, that is, the risk protection obtained by accounting for adverse volatility transmission from currencies to the respective ADRs. From the seminal paper of Glen and Jorion (1993), it is well known that the introduction of hedging instruments into an internationally exposed portfolio significantly reduces the portfolio volatility, and delivers higher Sharpe ratios. In terms of volatility spillovers, it is plausible that shocks in currencies will also affect the USD-traded ADRs and the optimal portfolio weights will consequently be adjusted. Therefore, it is of great interest to determine the possible gains in portfolio variance forecasting; also with regards to specific spillover.

Each different specification of the the WAR, leads to a particular dynamics of the volatility transmission to future values. This is achieved by imposing a structure on the autoregressive matrix M. Based upon these last and previous considerations, we propose the following structure:

1. Absence of risk spillover: $M$ diagonal or Diagonal WAR model;

2. Currency-risk spillover: $M$ has non-zero elements on its diagonal and on the diagonal of its block $N-1, N$; or Diagonal WAR model with currency-risk spillover;

3. Limited-risk spillover: $M$ block-diagonal or Block-diagonal WAR;

4. Pervasive-risk spillover: $M$ block-diagonal and non-zero block $N-1, N$, or Block-diagonal WAR and currency-risk spillover;

5. Full-risk spillover: full $M$ or full WAR.

Specification (5) assumes that risk spillover effects occur across all the 15 assets included in the portfolio, and thus also across equities in different economic sectors. This represents the optimal but infeasible benchmark, while the other four cases are restricted versions of (5). The opposite specification is (1) where the diagonality of matrix $M$ leads to the absence of risk spillovers across assets, and the dynamic of each variance and covariance is driven by just its

\footnotetext{
${ }^{3}$ Where in our empirical example the currencies consitute a group of assets.
} 
own past. Specification (2) is an enriched version of (1) as it considers a possible risk spillover from currencies to ADRs, but it does not allow for other forms of risk spillover. We stress that such a design coincides with the presence in the $M$ matrix of the previously introduced (Section 2) diagonal sub-matrix $M_{N-1, N}$. In case (3) we cluster assets according to their industrial sector (or as pro-cyclical/anti-cyclical). That is, we only allow 5 (or 3) groups with risk spillover effects. Risk spillovers therefore exist across equities included in the same economic sector and within currencies, but there is no risk spillover across equities in different sectors or from currencies to equities. Specification (4) is different from (3) in that currency-risk spillover effects are permitted from currencies to ADRs only, as in (2). In particular, the volatility of the three ADRs will only be influenced by the past volatility of the corresponding exchange rate (provided that stocks and currency are properly ordered in the covariance matrix) and by the volatilities and covariances of the other ADRs. The two limiting cases (1) and (5) should both be considered as benchmarks: we expect to improve on (1) by introducing richer structures in $M$, and we strive not to be too far from (5) which is the ideal specification (from a statistical point of view).

\section{Evaluation of risk spillover}

The forecasted variance/covariance matrix is the best means of evaluating the benefits and losses associated with a limited structure on the risk spillover. Risk spillovers determine the effect on a given asset risk of past values of variances/covariances on future variances/covariances belonging to the entire set of assets (full-risk spillover), to the same asset class (limited riskspillover), to other different asset groups (currency-risk spillover) or to their own past only (no spillover).

In our empirical application forecasts are made one period ahead. We fix the estimation sample to 250 observations (one trading year) rolling it forward to produce the forecasts (thus using an estimating moving window of 250 trading days). The comparison of the alternative risk spillover design is therefore based on 1,509 covariance forecasts. At each point in time $t$, a

given model is used to produce a forecast of the covariance matrix $\hat{Y}_{t+1}$. The direct evaluation of the risk spillover impact will be based on the covariance forecasts, and on their comparison with the true covariances as proxied by the realized covariances. As a further evaluation, we focus on optimal portfolio weights $\mathbf{w}_{t+1}$ computed at time $t$ using the predicted covariance for time $t+1$. At time $t+1$ portfolio returns are computed using the expected optimal weights (function of 
$\left.\hat{Y}_{t+1}\right)$ and the realized returns on the assets. An alternative approach would also be to introduce a forecasting equation for the returns, but a model involving the conditional mean is beyond the scope of our research, which focuses purely on the role of the variance.

\subsection{Forecasting evaluation}

An affective way of directly evaluating the implications of a limited risk spillover is to adopt a pure forecasting perspective. We thus evaluate and compare the out-of-sample forecasted variance/covariance matrices provided by the models under analysis with the true covariance, as proxied by the observed realized covariance. In this way, the comparison across the competing model designs described in Section 4 will permit evaluation of the impact of limited-risk and currency-risk spillover, as well as their combination (the pervasive-risk spillover).

Our comparison of alternative WAR specifications makes use of two loss functions for multivariate volatility models. Following Patton and Sheppard (2009), and Clements et al. (2009), we consider the following loss functions:

$$
\begin{aligned}
& L_{t+1, i}^{1}=\frac{1}{k^{2}} \operatorname{vec}\left(\hat{Y}_{t+1, i}-Y_{t+1}\right)^{\prime} \operatorname{vec}\left(\hat{Y}_{t+1, i}-Y_{t+1}\right), \\
& L_{t+1, i}^{2}=\operatorname{trace}\left(\left(\hat{Y}_{t+1, i}\right)^{-1} Y_{t+1}\right)-\log \left(\left|\left(\hat{Y}_{t+1, i}\right)^{-1} Y_{t+1}\right|\right) .
\end{aligned}
$$

which are derived from Patton and Sheppard (2009). The function $L_{t+1, i}^{1}$ is a multivariate mean squared error function, while $L_{t+1}^{2}$ is included in the class of robust loss functions defined in Patton and Sheppard (2009). It it is similar to a quasi-likelihood loss function. We also note that these loss functions are included in the class of consistent functions defined in Laurent et al. (2009).

To verify the null that $E\left[L_{i, t+1}^{w}\right]=E\left[L_{j, t+1}^{w}\right], w=1,2$ we could use a Diebold-Mariano-type test (see Diebold and Mariano, 1995, and West, 1996), computing the test statistic:

$$
\begin{aligned}
d_{i j, t+1}^{w} & =L_{i, t}^{w}-L_{j, t}^{w} \\
L_{i j}^{w} & =\frac{\bar{d}_{i j}^{w}}{\sqrt{\operatorname{Var}\left(\bar{d}_{i j}^{w}\right)}}
\end{aligned}
$$

where $\bar{d}_{i j}^{w}=\frac{1}{W} \sum_{l=1}^{W} d_{i j, t+1}^{w}$, and $\operatorname{Var}\left(\bar{d}_{i j}^{w}\right)$ is obtained by a HAC estimator. However, other methods are needed to consider alternative models. Some popular approaches are the Reality Check of White (2000), the Superior Predictive Ability test of Hansen (2005), and the Model Confidence Set (MCS) of Hansen et al. (2003), Hansen et al. (2011). 
Here, we consider the method of Hansen et al. (2011), which allows us to create a set of models whose forecasting performances are statistically equivalent. The MCS uses all pairwise loss differentials $d_{i j, t}^{w}$ as inputs for a given loss function $w$ and for all $i, j=1,2, . . P, i \neq j$, where $P$ is the total number of fitted models. The MCS then proceeds by performing a sequential elimination procedure test on a set of models $\mathcal{M}_{l}$ according to the following null hypothesis $H_{0}: E\left[\bar{d}_{i j, t+1}^{w}\right]=0$, with $i>j$ and for all $i, j \in \mathcal{M}_{l}$. The initial set $\mathcal{M}_{1}$ contains all models, and if the null hypothesis is rejected, the worst performing model is excluded from the set. The procedure then works iteratively until the null is not rejected. Each step thus performs two operations at a generic iteration $l$ : verifying the null hypothesis and stopping if accepted; if the null is rejected, identifying the worst-performing model and removing it from the set. To verify the null hypothesis, Hansen et al. (2003) proposed two distinct test statistics, based on the quantity (7). The difference here is that the variance is computed using a bootstrap procedure (see Hansen et al. (2011) for further details). The two statistics are the following:

$$
\begin{aligned}
T_{R} & =\max _{i, j \in \mathcal{M}}\left|L_{i j}^{w}\right|, \\
T_{S Q} & =\sum_{i, j \in \mathcal{M}, i>j}\left(L_{i j}^{w}\right)^{2} .
\end{aligned}
$$

Given that the models produce covariances across the forecasts that are not null, the test statistics are distributed in a complex and non-standard manner. A bootstrap approach has been proposed by Hansen et al. (2011) to determine the p values of the test statistic. For a specific confidence level $\alpha$, the null hypothesis can thus be verified by determining the bootstrapped $\mathrm{p}$ values. If it is rejected, the worst performing model is identified as:

$$
i=\arg \max _{i \in \mathcal{M}} \sum_{j \in \mathcal{M}} \bar{d}_{i j}^{w}\left(\operatorname{Var}\left(\sum_{j \in \mathcal{M}} \bar{d}_{i j}^{w}\right)\right)^{-1} .
$$

The MCS method was originally proposed for the comparison of univariate volatility forecasts but Patton and Sheppard (2009) suggest that it could also be of interest in the multivariate framework, a claim supported by the analysis in Clements et al. (2009). In this paper, the MCS will be used as a tool for the comparison of the forecasting performances of nested models. The purpose of this is to verify two null hypotheses: first, that a restricted model provides forecasts statistically equivalent to those produced by an unrestricted model; second, that the introduction of currency risk spillovers improves the covariance forecast performances. 


\subsection{Economic evaluation}

A direct approach, although appealing and easy to implement, lacks of an economic interpretation of the results. In fact, the benefit of choosing the best forecasting model is not clear for the representative agent investing in the theoretical portfolio.

We are thus keen to adopt a more interpretable approach whereby we can discriminate between the plethora of models available. This is why we choose to evaluate the forecast performances of alternative variance/covariance models in economic terms. We prefer to compar models using indirect means. An indirect approach does not permit direct evaluation of the ability of the covariance models to compute accurate forecasts, but it does make it possible to consider the economic criteria associated with each model's forecasting power. In this paper, we consider how the choice of different models can affect an asset allocation framework by contrasting the performance of two types of portfolios:

- Equally weighted portfolio, denoted as EW, which is not exposed to the asset return mean estimation error and it is superior to many other portfolios (see DeMiguel et al., 2009),

- Global minimum variance portfolio with and without short-selling constraints denoted as GMV and GMVB, respectively.

The weights of the equally weighted portfolios are $\mathbf{w}=\mathbf{1}_{n} / n$, where $\mathbf{1}_{n}$ denotes the $n$-dimensional vector of unit elements. Note that this portfolio offers a perfect hedge to the currency risk associated to the ADRs since the amount invested in stocks is the same as that invested in USD against the stock's home currency.

The GMV weights are time- and model-dependent. Their derivation is based on the covariance forecast:

$$
\mathbf{w}_{t+h}=\frac{\hat{Y}_{t+1}^{-1} \mathbf{1}}{\mathbf{1}^{\prime} \hat{Y}_{t+1} \mathbf{1}}
$$

with $\hat{Y}_{t+1}$ denoting the one-step ahead forecasted covariance matrix based on the information set up to time $t$.

GMVB weights are determined by solving the optimization problem:

$$
\begin{aligned}
\arg \min & \mathbf{w}^{\prime} \hat{Y}_{t+1} \mathbf{w} \\
\text { s.t. } & w_{j} \geq 0 \quad j=1, \ldots, n \\
\text { and } & \mathbf{w}^{\prime} \mathbf{1}=1 .
\end{aligned}
$$


For the different variance forecasting models and portfolio allocation weights, we then define the following quantities:

(A1) Realized portfolio returns: $\quad r_{t+1}=\omega_{t+1} \mathbf{r}_{t+1}$,

(A2) Expected portfolio returns: $\quad \hat{r}_{t+1}=\mathbf{w}_{t+1} \mathbf{r}_{t+1}$,

(B1) Realized portfolio variances: $\sigma_{t+1}^{2}=\omega^{\prime} Y_{t+1} \omega$,

(B2) Expected portfolio variances: $\hat{\sigma}_{t+1}^{2}=\mathbf{w}^{\prime} \hat{Y}_{t+1} \mathbf{w}$,

(C1) Realized Sharpe ratio: $\quad S_{t+1}=\frac{r_{t+1}}{\sqrt{\left(s_{t+1}\right)}}$,

(C2) Expected Sharpe ratio: $\quad \hat{S}_{t+1}=\frac{\hat{r}_{t+1}}{\sqrt{\left(h_{t+1}\right)}}$,

where $\omega$ denotes the ex-post solution to the optimization problem in equation (11), i.e. if the realization of $Y_{t+1}$ were observed. A1, B1 and C1 represent a sort of 'Oracle prediction', as used in Chiriac and Voev (2010).

The methods we apply for the indirect model evaluation use the MSE and QLIKE univariate loss function:

$$
\begin{aligned}
& l f_{t+1}^{1}=\left(\hat{\sigma}_{t+1}^{2}-\sigma_{t+1}^{2}\right)^{2}, \\
& l f_{t+1}^{2}=\log \left(\hat{\sigma}_{t+1}^{2}\right)+\sigma_{t+h}^{2} \hat{\sigma}_{t+1}^{-2} \\
& l f_{t+1}^{3}=\left(\hat{S}_{t+1}-S_{t+1}\right)^{2},
\end{aligned}
$$

Loss functions (12) and (13) are similar to those adopted in the direct model evaluation and consider the ex-post realized portfolio volatility as targets, i.e. the volatility computed once the optimal covariance matrix is known and optimal weights have been computed. Loss function (14) is slightly different in the sense that it considers what we dubbed realized Sharpe ratio. Since we observe both returns and volatility at every point in time, it makes sense to construct a series of Sharpe ratios which do not arise simply as the ratio between total expected returns and sample portfolio volatility, but which provide the ratio between expected (i.e. forecasted) portfolio returns and expected portfolio volatilities for every forecasted value. Both expected returns and expected portfolio volatility are strictly dependent on the forecasted covariance matrix. Our target will therefore not be to maximize this expected Sharpe ratio, but to minimize the distance between this ex-post realized ratio and the expected one. The indirect evaluation of the models then proceeds using the MCS approach previously discussed. 


\subsection{Empirical results}

Table 3 and 4 reports the results of the out-of-sample forecasting exercise for the two evaluation approaches examined earlier. Each entry reports the average values of the loss function used for the five models. Cells marked in grey indicate that the corresponding model belongs to the $5 \%$ MCS. Along with the values of the loss function computed on the entire sample, we also reported the results for subperiods which takes the year 2003 as the starting estimation window and then cover the period from 2004 to 2008. This was done to check if the recent financial crisis, which peaked in early 2009 , had any influence on how the optimal model was defined.

Although the evidence is not striking, the direct evaluation of the covariance matrix forecasts displays a preference for the diagonal WAR with currency-risk spillover effects. Loss function $L^{1}$ tends to identify all the models as the best models, with the exception of the full WAR, which represents the full risk spillover case. However, within the set of best performing models only the quasi-likehood loss function $L^{2}$ accepts the diagonal WAR with spillover (limited risk spillover). Note that these results are robust for the different periods under analysis.

When an equally-weighted portfolio is constructed, no model clearly outperforms another when the volatility MSE loss function is used. The realized Sharpe ratio suggests similar MSE results, but with some preference for the most detailed models (full risk spillover). In that case, under the cyclical asset grouping, currency risk spillover makes the forecasts of the blockdiagonal model statistically equivalent to those of the full model, and statistically preferable to those of the block-diagonal specification without currency risk spillovers, illustrated in Table 4 . This finding implies that the pervasive-risk spillover model represents the preferred solution. As regards to the use of the QLIKE univariate loss function, it is preferable to choose the most parameterized models which lead to full risk spillover, and limited risk spillover, both when it is combined with currency-risk spillover and when it is not. The inclusion of the block diagonal models highlights the importance of considering risk-spillovers within groups. This might be because the weights are fixed a priori, so more information is conveyed in the forecasts by more structured models ${ }^{4}$. This is the opposite of the results obtained when using GMV and the GMV with portfolios optimized with short-selling constraints. These two approaches are coherent in that both use the least parameterized models (diagonal), with or without currency-risk spillover

\footnotetext{
${ }^{4}$ More detailed model structure correspond to a greater complexity in risk spillover structures.
} 
effects. The results are robust no matter which MCS statistic and data sample is considered. Note, however, that the diagonal model, which takes into account the volatility transmission from currencies to ADRs, is generally recognized as preferable to its simpler counterpart. This might be explained in the following way: It is commonly acknowledged that an optimal portfolio, established using parameterized models, will carry some estimation errors. The impact of estimation errors can be so significant that recent studies (e.g. DeMiguel et al., 2009) suggest that no model can beat a simple equally-weighted portfolio. Therefore, in the case of this research, a trade-off arises between the number of parameters in the model which minimize the estimation errors and its ability to effectively capture all relevant kinds of risk. The diagonal model which accounts for currency-risk spillover effects is proven to be most effective framework of resolving challenges associated with this trade-off. On the one hand, it is parsimonious, as it recognizes that the risk of portfolio assets is influenced by their past alone (diagonal $M$ ). On the other hand, it also accounts for the volatility transmission between currencies and for correspondent ADR currency-risk spillover component, capturing features that the simple diagonal model (absence of risk spillover) does not.

A different interpretation to the results obtained in the analysis, with a particular focus on the GMV and constrained GMV allocation, relates to the very nature of our theoretical portfolio. Although grouped according to their sector or their cyclicality, the assets under consideration represent a good example of a well diversified portfolio. It therefore comes as no surprise that spillover effects are only evident between ADRs and FX and are mixed in other sectors. ADR are affected by shocks to exchange rate volatilities. This becomes increasingly relevant in a global minimum variance optimization framework and our results support this argumentation.

\subsection{Robustness check}

To corroborate our results and to assess the role played by the latest financial crisis, we performed a robustness check by splitting the data into sample periods. By keeping the starting point fixed (year 2003), we only considered forecasted values up to 2006, 2007 and 2008, respectively. The main reason for this was to verify whether the results alter in accordance with the evaluation period, in particular when this considers ranges before and during the 2008 financial crisis. As we did previously, we employed direct and indirect criteria to evaluate the impact of assuming limitation in the volatility transmission dynamics. Results are reported in 
Tables 5 to 8 . Again, pure statistical methods tend to prefer a diagonal model which considers currency-risk spillover effects between currencies and ADRs. When it comes to analysis of economic criteria, a passive portfolio (the EW which has fixed weights) does not particularly discriminate between models (loss function $L^{1}$ ) nor does it tend to select the less parsimonious full WAR models (full risk spillover) or the block diagonal WAR models (limited risk spillover). On the contrary, optimized portfolios (with or without short-selling constraints) favor the least parametrized models (absence of risk spillover), but they also highlight the importance of taking the currency-risk spillover into consideration.

\section{Conclusions}

We investigated the benefits of considering volatility spillover risks in a international equity portfolio. Spillover risk is defined as the danger of adverse transmissions of return variances and covariances from one specific asset category to another. We focused in particular on the volatility transmission between foreign stocks traded at NYSE (as ADR) and their home country's exchange rates (against the U.S. dollar).

We first introduced a set of specific parameterizations that allow us to control for diverse definitions of spillover risk. This is done by imposing a particular structure on the model's coefficients. Our approach relies on the Wishart autoregressive model (WAR) proposed by Gourieroux et al. (2009). The model is based on a dynamic extension of the Wishart distribution. This specification is compatible with financial theory, satisfies the constraints on volatility matrices, and, more importantly, its form is flexible, while maintaining the coefficients' interpretability.

The assessment of the economic implications of accounting for risk spillover is then performed in a forecasting framework. The forecasting ability of several model specifications is evaluated both in statistical and economic terms. On the economic side, the crucial mechanism is that the optimized portfolio weights depend on how spillovers are structurally modeled. Consistent with the recent literature on realized volatility, the empirical analysis is based on ultrahigh frequency data of 12 stocks quoted on U.S. equity markets (three of which are ADR) and three exchange rates over a period of seven years that includes the recent financial crisis. As a result, the forecasting analysis shows that considering only sector- and currency-risk spillovers, rather than full spillover, is viable both in economic and statistical terms. 


\section{References}

Aielli, G. And M. Caporin (2011): “Variance Clustering Improved Dynamic Conditional Correlation MGARCH Estimators," Working Paper - Department of Economics and Management, University of Padova.

Andersen, T., T. Bollerslev, F. Diebold, and P. Labys (2003): “Modeling and forecasting realized volatility," Econometrica, 71, 579-625.

Asai, M., M. Caporin, and M. McAleer (2008): "Block structure multivariate stochastic volatility," Manuscript.

BANDI, F. AND J. Russel (2008): “Microstructure noise, realized volatility and optimal sampling," Review of Economic Studies, 75, 339-369.

Barndorff-Nielsen, O., P. Hansen, A. Lunde, and N. Shephard (2008a): “Designing Realized Kernels in to Measure the Ex-Post Variation of Equity Prices in the Presence of Noise," Econometrica, 76, 1481-1536.

_ (2008b): "Multivariate realised kernels: consistent positive semi-definite estimators of the covariation of equity prices with noise and non-synchronous trading," manuscript.

Barndorff-Nielsen, O. ANd N. Shephard (2004): "Econometric analysis of realized covariation: high-frequency based covariance, regressions, and correlation in financial economics," Econometrica, 72, 885-925.

Bauwens, L. . And J. Rombouts (2007): “Bayesian Clustering of Many Garch Models," Econometric Reviews, 26, 365-386.

Billio, M. and M. Caporin (2008): “A generalised dynamic conditional correlation model for portfolio risk evaluation," Mathematics and Computers in Simulations, forthcoming.

Billio, M., M. Caporin, and M. Gobbo (2006): "Flexible dynamic conditional correlation multivariate GARCH for asset allocation," Applied Financial Economics Letters, 2, 123-130.

Bonato, M. (2009): "Estimating the degrees of freedom of the realized volatility Wishart autoregressive model," Manuscript. 
Bonato, M., M. Caporin, And A. Ranaldo (2008): “Forecasting realized (co)variances with a block structure Wishart autoregressive model," manuscript.

Campbell, J., K. S. de Medeiros, and L. Viceira (2010): “Global Currency Hedging,” The Journal of Finance, LXV.

Caporin, M. and P. Paruolo (2008): "Spatial dependence in multivariate volatility models," Working Paper.

Chiriac, R. and V. Voev (2010): “Modelling and forecasting multivariate realized volatility," Journal of Applied Econometrics (forthcoming).

Clements, A., M. Doolan, S. Hurn, and R. Becker (2009): “On the efficacy of techniques for evaluating multivariate volatility forecasts," NCER Working Paper Series 41, National Centre for Econometric Research.

De Pooter, M., M. Martens, And D. van Dijk (2006): "Predicting the daily covariance matrix for S\&P 100 stocks using intraday data - But which frequency to use?" Econometric Reviews, forthcoming.

DeMiguel, V., L. Garlappi, and R. Uppal (2009): “Optimal Versus Naive Diversification: How Inefficient is the 1/N Portfolio Strategy?" Review of Financial Studies, 22, 1915-1953.

Diebold, F. AND R. Mariano (1995): “Comparing predictive accuracy,” Journal of the Americal Statistical Association, 13, 253-263.

Engle, R. And B. Kelly (2008): “Dynamic Equicorrelations,” Working Paper.

GLEN, J. AND P. JoRion (1993): “Currency hedging for international portfolios," The Journal of Finance, 48, 1865-1886.

Gourieroux, C., J. Jasiak, AND R. Sufana (2009): “The Wishart autoregressive process of multivariate stochastic volatility," Journal of Econometrics, 150, 167-181, forthcoming.

Hansen, P. And A. Lunde (2006): “Realized variance and market microstructure noise," Journal of Business and Economic Statistics, 24, 127-218.

Hansen, P., A. Lunde, And J. Nason (2003): “Choosing the best volatility models: the model confidence set approach," Oxford Bulletin of Economics and Statistics, 65, 839-861. 
_ (2011): “The Model Confidence Set," Econometrica, fortcoming.

Hansen, P. R. (2005): “A Test for Superior Predictive Ability," Journal of Business and Economic Statistics, 23, 365-380.

Laurent, S., J. Rombouts, and F. Violante (2009): “On loss functions and ranking forecasting performances of multivariate GARCH models," CIRANO working paper.

Lunde, A. And V. Voev (2007): “Integrated Covariance Estimation Using High-Frequency Data in the Presence of Noise," Journal of Finacial Econometrics, 5, 68-104.

Mancino, M. and S. Sanfelici (2008): "Estimating Covariance Via Fourier Method in the Presence of Asynchronous Trading and Microstructure Noise," manuscript.

Muirhead, R. (1982): Aspects of multivariate statistical theory, Whiley Series in Probability and Mathematical Statistics.

Patton, A. J. ANd K. Sheppard (2009): “Optimal combinations of realised volatility estimators,” International Journal of Forecasting, 25, 218 - 238.

SHEPPARD, K. (2006): “Realized covariance and scrambling," Manuscript.

West, K. (1996): “Asymptotic inference about predictive ability,” Econometrica, 64, 1067-1084.

White, H. (2000): “A reality check for data snooping,” Econometrica, 68, 1097-1126.

Zhang, L. (2010): "Estimating covariation: Epps effect, microstructure noise." Journal of Econometrics, 160, 33-47.

Zhang, L., P. Mykland, and Y. A. Sahalia (2005): "A tale of two time scales: Determining integrated volatility with noisy high-frequency data," Journal of the American Statistical Association, 100, 1394-1411. 
Table 3: Average values of the direct loss functions implemented for the different portfolios. A grey cell indicates that the model belongs to the $5 \% \mathrm{MCS}$, according to both $T_{R}$ and $T_{S Q}$.

\begin{tabular}{c|ccc|c|c} 
Model & $L^{1}$ & $L^{2}$ & $L^{1}$ & $L^{2}$ \\
Clustering & \multicolumn{2}{|c}{ Sectorial } & \multicolumn{2}{c}{ Cyclical } \\
\hline Full & 4.155 & 277.943 & 4.155 & 277.943 \\
Diagonal & 3.188 & 30.983 & 3.187 & 30.983 \\
Block diagonal & 3.448 & 41.142 & 3.536 & 53.601 \\
Diagonal spill. & 3.177 & 21.911 & 3.176 & 21.910 \\
Block diag. spill. & 3.431 & 46.512 & 3.603 & 22.362
\end{tabular}

Table 4: Average values of the direct loss functions implemented for the different portfolios. A grey cell indicates that the model belongs to the $5 \%$ MCS, according to both $T_{R}$ and $T_{S Q} \cdot{ }^{a}$ and ${ }^{b}$ indicate that it belongs to the $5 \%$ MCS according only to $T_{R}$ or $T_{S Q}$, respectively.

\begin{tabular}{c|ccc|ccc|ccc} 
Model & \multicolumn{3}{|c|}{$1 / \mathrm{N}$} & \multicolumn{3}{|c|}{ GMV } & \multicolumn{3}{c}{ GMVr } \\
Sectorial & $l f^{1}$ & $l f^{2}$ & $l f^{3}$ & $l f^{1}$ & $l f^{2}$ & $l f^{3}$ & $l f^{1}$ & $l f^{2}$ & $l f^{3}$ \\
\hline Full & 1.878 & 0.028 & 0.074 & 0.029 & -2.696 & 12.653 & 0.095 & -2.417 & 5.140 \\
Diagonal & 1.347 & 0.044 & 0.084 & 0.000 & -3.593 & 2.114 & 0.000 & -3.448 & 1.515 \\
Block diagonal & 1.495 & 0.026 & 0.079 & 0.000 & -3.377 & 3.046 & 0.000 & -3.261 & 2.040 \\
Diagonal spill. & 1.351 & 0.042 & 0.083 & 0.000 & -3.686 & 1.789 & 0.000 & -3.538 & 1.275 \\
Block diag. spill. & 1.493 & 0.025 & 0.078 & 0.000 & -3.525 & 4.109 & 0.000 & -3.375 & 1.991 \\
\hline Cyclical & & & & & & & & & \\
Full & 1.878 & 0.028 & 0.074 & 0.029 & -2.696 & 12.653 & 0.095 & -2.417 & 5.140 \\
Diagonal & 1.347 & 0.044 & 0.084 & 0.000 & -3.593 & 2.114 & 0.000 & -3.448 & 1.515 \\
Block Diagonal & 1.441 & 0.021 & 0.077 & 0.003 & -2.954 & 5.483 & 0.005 & -2.858 & 3.936 \\
Diagonal spill. & 1.351 & 0.042 & 0.083 & 0.000 & -3.686 & 1.789 & 0.000 & -3.538 & 1.275 \\
Block diag. spill. & 1.594 & 0.013 & 0.073 & 0.000 & -3.668 & 1.866 & 0.000 & -3.532 & 1.316
\end{tabular}


Table 5: Average values of the direct loss functions implemented for the different portfolios and the sectorial cluster. A grey cell indicates that the model belongs to the $5 \%$ MCS, according to both $T_{R}$ and $T_{S Q}$.

\begin{tabular}{c|cc|} 
Model & $L^{1}$ & $L^{2}$ \\
\hline 2003-2006 & & \\
Full & 0.427 & 56.109 \\
Diagonal & 0.382 & 31.129 \\
Block diagonal & 0.384 & 40.770 \\
Diagonal spill. & 0.380 & 21.885 \\
Block diag. spill. & 0.385 & 37.559 \\
\hline 2003-2007 & & \\
Full & 0.409 & 54.349 \\
Diagonal & 0.369 & 30.458 \\
Block diagonal & 0.372 & 39.236 \\
Diagonal spill. & 0.366 & 21.941 \\
Block diag. spill. & 0.371 & 43.737 \\
\hline 2003-2008 & & \\
Full & 4.469 & 210.381 \\
Diagonal & 3.522 & 31.174 \\
Block diagonal & 3.825 & 41.292 \\
Diagonal spill. & 3.517 & 22.043 \\
Block diag. spill. & 3.812 & 50.931
\end{tabular}


Table 6: Average values of the direct loss functions implemented for the different portfolios and the sectorial cluster. A grey cell indicates that the model belongs to the $5 \%$ MCS, according to both $T_{R}$ and $T_{S Q} \cdot{ }^{a}$ and ${ }^{b}$ indicate that it belongs to the $5 \% \mathrm{MCS}$, according only to $T_{R}$ or $T_{S Q}$, respectively.

\begin{tabular}{c|ccc|ccc|ccc} 
Model & \multicolumn{3}{|c}{$1 / \mathrm{N}$} & \multicolumn{3}{|c}{ GMV } & \multicolumn{3}{c}{ GMVr } \\
Sectorial & $l f^{1}$ & $l f^{2}$ & $l f^{3}$ & $l f^{1}$ & $l f^{2}$ & $l f^{3}$ & $l f^{1}$ & $l f^{2}$ & $l f^{3}$ \\
\hline $\begin{array}{c}\text { 2003-2006 } \\
\text { Full }\end{array}$ & 0.020 & -0.472 & 0.056 & 0.001 & -3.174 & 5.624 & 0.001 & -3.105 & 4.358 \\
$\begin{array}{c}\text { Diagonal } \\
\text { Block diagonal }\end{array}$ & 0.018 & -0.476 & 0.055 & 0.000 & -3.884 & 1.403 & 0.000 & -3.805 & 1.129 \\
Diagonal spill. & 0.016 & -0.485 & 0.053 & 0.000 & -3.521 & 3.351 & 0.000 & -3.471 & 2.373 \\
Block diag. spill. & 0.016 & -0.475 & 0.055 & 0.000 & -3.925 & 1.350 & 0.000 & -3.859 & 0.913 \\
\hline 2003-2007 & & & & & & & & & \\
Full & 0.031 & -0.436 & 0.068 & 0.001 & -3.183 & 4.959 & 0.001 & -3.105 & 3.694 \\
Diagonal & 0.031 & -0.430 & 0.073 & 0.000 & $-3.895^{a}$ & 1.400 & 0.000 & -3.782 & 1.114 \\
Block diagonal & 0.030 & -0.442 & 0.073 & 0.000 & -3.544 & 2.883 & 0.000 & -3.479 & 1.988 \\
Diagonal spill. & 0.031 & -0.431 & 0.073 & 0.000 & -3.950 & 1.172 & 0.000 & -3.844 & 0.823 \\
Block diag. spill. & 0.029 & -0.443 & 0.072 & 0.000 & -3.802 & 3.030 & 0.000 & -3.705 & 1.437 \\
\hline 2003-2008 & & & & & & & & & \\
Full & 2.064 & -0.137 & 0.074 & 0.016 & -2.905 & 7.757 & 0.053 & -2.737 & 3.893 \\
Diagonal & 1.518 & -0.126 & $0.084^{a}$ & 0.000 & -3.719 & 1.284 & 0.000 & -3.576 & 1.020 \\
Block diagonal & 1.706 & -0.141 & 0.080 & 0.000 & -3.412 & 2.676 & 0.000 & -3.314 & 1.826 \\
Diagonal spill. & 1.522 & -0.128 & 0.083 & 0.000 & -3.758 & 1.285 & 0.000 & -3.621 & 0.903 \\
Block diag. spill. & $1.702^{b}$ & -0.143 & 0.079 & 0.000 & -3.635 & 3.726 & 0.000 & -3.507 & 1.463 \\
\hline
\end{tabular}


Table 7: Average values of the direct loss functions implemented for the different portfolios and the cyclical cluster. A grey cell indicates that the model belongs to the $5 \% \mathrm{MCS}$, according to both $T_{R}$ and $T_{S Q}$.

\begin{tabular}{c|cc|} 
Model & $L^{1}$ & $L^{2}$ \\
\hline 2003-2006 & & \\
Full & 0.427 & 56.109 \\
Diagonal & 0.382 & 31.129 \\
Block diagonal & 0.395 & 34.424 \\
Diagonal spill. & 0.380 & 21.885 \\
Block diag.spill. & 0.390 & 22.035 \\
\hline 2003-2007 & & \\
Full & 0.409 & 54.349 \\
Diagonal & 0.369 & 30.458 \\
Block diagonal & 0.383 & 33.777 \\
Diagonal spill. & 0.366 & 21.941 \\
Block diag.spill & 0.378 & 22.106 \\
\hline 2003-2008 & & \\
Full & 4.469 & 210.381 \\
Diagonal & 3.522 & 31.174 \\
Block diagonal & 3.869 & 47.885 \\
Diagonal spill. & 3.517 & 22.043 \\
Block diag.spill. & 3.986 & 22.369
\end{tabular}


Table 8: Average values of the direct loss functions implemented for the different portfolios and the cyclical cluster. A gray cell indicates that the model belongs to the $5 \% \mathrm{MCS}$, according to both $T_{R}$ and $T_{S Q} \cdot{ }^{a}$ and ${ }^{b}$ indicate that it belongs to the $5 \%$ MCS according only to $T_{R}$ or $T_{S Q}$, respectively.

\begin{tabular}{|c|c|c|c|c|c|c|c|c|c|}
\hline \multirow{2}{*}{$\begin{array}{c}\text { Model } \\
\text { Sectorial }\end{array}$} & \multicolumn{3}{|c|}{$1 / \mathrm{N}$} & \multicolumn{3}{|c|}{ GMV } & \multicolumn{3}{|c|}{ GMVr } \\
\hline & $l f^{1}$ & $l f^{2}$ & $l f^{3}$ & $l f^{1}$ & $l f^{2}$ & $l f^{3}$ & $l f^{1}$ & $l f^{2}$ & $l f^{3}$ \\
\hline \multicolumn{10}{|l|}{$2003-2006$} \\
\hline Full & 0.020 & -0.472 & $\mathrm{t} 0.056^{a}$ & 0.001 & -3.174 & 5.624 & 0.001 & -3.105 & 4.358 \\
\hline Diagonal & $0.018^{a}$ & -0.476 & $0.055^{a}$ & 0.000 & $-3.884^{a}$ & 1.403 & 0.000 & $-3.805^{a}$ & 1.129 \\
\hline Block diagonal & 0.017 & -0.484 & $0.054^{a}$ & 0.001 & -3.215 & 5.506 & 0.001 & -3.168 & 4.316 \\
\hline Diagonal spill. & $0.018^{a}$ & -0.475 & $0.055^{a}$ & 0.000 & -3.925 & 1.350 & 0.000 & -3.859 & 0.913 \\
\hline Block diag.spill. & 0.016 & -0.490 & 0.050 & 0.000 & -3.924 & 1.358 & 0.000 & -3.858 & 0.922 \\
\hline \multicolumn{10}{|l|}{$2003-2007$} \\
\hline Full & 0.031 & -0.436 & 0.068 & 0.001 & -3.183 & 4.959 & 0.001 & -3.105 & 3.694 \\
\hline Diagonal & 0.031 & -0.430 & 0.073 & 0.000 & -3.895 & 1.400 & 0.000 & -3.782 & 1.114 \\
\hline Block diagonal & 0.030 & -0.443 & 0.073 & 0.001 & -3.241 & 4.763 & 0.001 & -3.189 & 3.626 \\
\hline Diagonal spill. & 0.031 & -0.431 & 0.073 & 0.000 & -3.950 & 1.172 & 0.000 & -3.844 & 0.823 \\
\hline Block diag.spill. & 0.029 & -0.450 & 0.070 & 0.000 & -3.952 & 1.174 & 0.000 & -3.853 & 0.803 \\
\hline \multicolumn{10}{|l|}{$2003-2008$} \\
\hline Full & 2.064 & -0.137 & 0.074 & 0.016 & -2.905 & 7.757 & $0.053^{a}$ & -2.737 & 3.893 \\
\hline Diagonal & 1.518 & -0.126 & $0.084^{a}$ & 0.000 & -3.719 & 1.284 & 0.000 & -3.576 & 1.020 \\
\hline Block diagonal & 1.637 & -0.146 & 0.078 & 0.002 & -3.079 & 4.662 & $0.003^{a}$ & -3.006 & 3.318 \\
\hline Diagonal spill. & 1.522 & -0.128 & 0.083 & 0.000 & -3.758 & 1.285 & 0.000 & -3.621 & 0.903 \\
\hline Block diag.spill. & 1.825 & -0.153 & 0.074 & 0.000 & -3.761 & 1.267 & 0.000 & -3.634 & 0.859 \\
\hline
\end{tabular}




\section{Swiss National Bank Working Papers published since 2004:}

2004-1 Samuel Reynard: Financial Market Participation and the Apparent Instability of Money Demand

2004-2 Urs W. Birchler and Diana Hancock: What Does the Yield on Subordinated Bank Debt Measure?

2005-1 Hasan Bakhshi, Hashmat Khan and Barbara Rudolf: The Phillips curve under state-dependent pricing

2005-2 Andreas M. Fischer: On the Inadequacy of Newswire Reports for Empirical Research on Foreign Exchange Interventions

2006-1 Andreas M. Fischer: Measuring Income Elasticity for Swiss Money Demand: What do the Cantons say about Financial Innovation?

2006-2 Charlotte Christiansen and Angelo Ranaldo: Realized Bond-Stock Correlation: Macroeconomic Announcement Effects

2006-3 Martin Brown and Christian Zehnder: Credit Reporting, Relationship Banking, and Loan Repayment

2006-4 Hansjörg Lehmann and Michael Manz: The Exposure of Swiss Banks to Macroeconomic Shocks - an Empirical Investigation

2006-5 Katrin Assenmacher-Wesche and Stefan Gerlach: Money Growth, Output Gaps and Inflation at Low and High Frequency: Spectral Estimates for Switzerland

2006-6 Marlene Amstad and Andreas M. Fischer: Time-Varying Pass-Through from Import Prices to Consumer Prices: Evidence from an Event Study with Real-Time Data

2006-7 Samuel Reynard: Money and the Great Disinflation

2006-8 Urs W. Birchler and Matteo Facchinetti: Can bank supervisors rely on market data? A critical assessment from a Swiss perspective

2006-9 Petra Gerlach-Kristen: A Two-Pillar Phillips Curve for Switzerland

2006-10 Kevin J. Fox and Mathias Zurlinden: On Understanding Sources of Growth and Output Gaps for Switzerland

2006-11 Angelo Ranaldo: Intraday Market Dynamics Around Public Information Arrivals

2007-1 Andreas M. Fischer, Gulzina Isakova and Ulan Termechikov: Do FX traders in Bishkek have similar perceptions to their London colleagues? Survey evidence of market practitioners' views 
2007-2 Ibrahim Chowdhury and Andreas Schabert: Federal Reserve Policy viewed through a Money Supply Lens

2007-3 Angelo Ranaldo: Segmentation and Time-of-Day Patterns in Foreign Exchange Markets

2007-4 Jürg M. Blum: Why ‘Basel II’ May Need a Leverage Ratio Restriction

2007-5 Samuel Reynard: Maintaining Low Inflation: Money, Interest Rates, and Policy Stance

2007-6 Rina Rosenblatt-Wisch: Loss Aversion in Aggregate Macroeconomic Time Series

2007-7 Martin Brown, Maria Rueda Maurer, Tamara Pak and Nurlanbek Tynaev: Banking Sector Reform and Interest Rates in Transition Economies: Bank-Level Evidence from Kyrgyzstan

2007-8 Hans-Jürg Büttler: An Orthogonal Polynomial Approach to Estimate the Term Structure of Interest Rates

2007-9 Raphael Auer: The Colonial Origins Of Comparative Development: Comment. A Solution to the Settler Mortality Debate

2007-10 Franziska Bignasca and Enzo Rossi: Applying the Hirose-Kamada filter to Swiss data: Output gap and exchange rate pass-through estimates

2007-11 Angelo Ranaldo and Enzo Rossi: The reaction of asset markets to Swiss National Bank communication

2007-12 Lukas Burkhard and Andreas M. Fischer: Communicating Policy Options at the Zero Bound

2007-13 Katrin Assenmacher-Wesche, Stefan Gerlach, and Toshitaka Sekine: Monetary Factors and Inflation in Japan

2007-14 Jean-Marc Natal and Nicolas Stoffels: Globalization, markups and the natural rate of interest

2007-15 Martin Brown, Tullio Jappelli and Marco Pagano: Information Sharing and Credit: Firm-Level Evidence from Transition Countries

2007-16 Andreas M. Fischer, Matthias Lutz and Manuel Wälti: Who Prices Locally? Survey Evidence of Swiss Exporters

2007-17 Angelo Ranaldo and Paul Söderlind: Safe Haven Currencies 
2008-1 Martin Brown and Christian Zehnder: The Emergence of Information Sharing in Credit Markets

2008-2 Yvan Lengwiler and Carlos Lenz: Intelligible Factors for the Yield Curve

2008-3 Katrin Assenmacher-Wesche and M. Hashem Pesaran: Forecasting the Swiss Economy Using VECX* Models: An Exercise in Forecast Combination Across Models and Observation Windows

2008-4 Maria Clara Rueda Maurer: Foreign bank entry, institutional development and credit access: firm-level evidence from 22 transition countries

2008-5 Marlene Amstad and Andreas M. Fischer: Are Weekly Inflation Forecasts Informative?

2008-6 Raphael Auer and Thomas Chaney: Cost Pass Through in a Competitive Model of Pricing-to-Market

2008-7 Martin Brown, Armin Falk and Ernst Fehr: Competition and Relational Contracts: The Role of Unemployment as a Disciplinary Device

2008-8 Raphael Auer: The Colonial and Geographic Origins of Comparative Development

2008-9 Andreas M. Fischer and Angelo Ranaldo: Does FOMC News Increase Global FX Trading?

2008-10 Charlotte Christiansen and Angelo Ranaldo: Extreme Coexceedances in New EU Member States' Stock Markets

2008-11 Barbara Rudolf and Mathias Zurlinden: Measuring capital stocks and capital services in Switzerland

2008-12 Philip Sauré: How to Use Industrial Policy to Sustain Trade Agreements

2008-13 Thomas Bolli and Mathias Zurlinden: Measuring growth of labour quality and the quality-adjusted unemployment rate in Switzerland

2008-14 Samuel Reynard: What Drives the Swiss Franc?

2008-15 Daniel Kaufmann: Price-Setting Behaviour in Switzerland - Evidence from CPI Micro Data

2008-16 Katrin Assenmacher-Wesche and Stefan Gerlach: Financial Structure and the Impact of Monetary Policy on Asset Prices

2008-17 Ernst Fehr, Martin Brown and Christian Zehnder: On Reputation: A Microfoundation of Contract Enforcement and Price Rigidity 
2008-18 Raphael Auer and Andreas M. Fischer: The Effect of Low-Wage Import Competition on U.S. Inflationary Pressure

2008-19 Christian Beer, Steven Ongena and Marcel Peter: Borrowing in Foreign Currency: Austrian Households as Carry Traders

2009-1 Thomas Bolli and Mathias Zurlinden: Measurement of labor quality growth caused by unobservable characteristics

2009-2 Martin Brown, Steven Ongena and Pinar Yeșin: Foreign Currency Borrowing by Small Firms

2009-3 Matteo Bonato, Massimiliano Caporin and Angelo Ranaldo: Forecasting realized (co)variances with a block structure Wishart autoregressive model

2009-4 Paul Söderlind: Inflation Risk Premia and Survey Evidence on Macroeconomic Uncertainty

2009-5 Christian Hott: Explaining House Price Fluctuations

2009-6 Sarah M. Lein and Eva Köberl: Capacity Utilisation, Constraints and Price Adjustments under the Microscope

2009-7 Philipp Haene and Andy Sturm: Optimal Central Counterparty Risk Management

2009-8 Christian Hott: Banks and Real Estate Prices

2009-9 Terhi Jokipii and Alistair Milne: Bank Capital Buffer and Risk Adjustment Decisions

2009-10 Philip Sauré: Bounded Love of Variety and Patterns of Trade

2009-11 Nicole Allenspach: Banking and Transparency: Is More Information Always Better?

2009-12 Philip Sauré and Hosny Zoabi: Effects of Trade on Female Labor Force Participation

2009-13 Barbara Rudolf and Mathias Zurlinden: Productivity and economic growth in Switzerland 1991-2005

2009-14 Sébastien Kraenzlin and Martin Schlegel: Bidding Behavior in the SNB's Repo Auctions

2009-15 Martin Schlegel and Sébastien Kraenzlin: Demand for Reserves and the Central Bank's Management of Interest Rates

2009-16 Carlos Lenz and Marcel Savioz: Monetary determinants of the Swiss franc 
2010-1 Charlotte Christiansen, Angelo Ranaldo and Paul Söderlind: The Time-Varying Systematic Risk of Carry Trade Strategies

2010-2 Daniel Kaufmann: The Timing of Price Changes and the Role of Heterogeneity

2010-3 Loriano Mancini, Angelo Ranaldo and Jan Wrampelmeyer: Liquidity in the Foreign Exchange Market: Measurement, Commonality, and Risk Premiums

2010-4 Samuel Reynard and Andreas Schabert: Modeling Monetary Policy

2010-5 Pierre Monnin and Terhi Jokipii: The Impact of Banking Sector Stability on the Real Economy

2010-6 Sébastien Kraenzlin and Thomas Nellen: Daytime is money

2010-7 Philip Sauré: Overreporting Oil Reserves

2010-8 Elizabeth Steiner: Estimating a stock-flow model for the Swiss housing market

2010-9 Martin Brown, Steven Ongena, Alexander Popov, and Pinar Yeșin: Who Needs Credit and Who Gets Credit in Eastern Europe?

2010-10 Jean-Pierre Danthine and André Kurmann: The Business Cycle Implications of Reciprocity in Labor Relations

2010-11 Thomas Nitschka: Momentum in stock market returns: Implications for risk premia on foreign currencies

2010-12 Petra Gerlach-Kristen and Barbara Rudolf: Macroeconomic and interest rate volatility under alternative monetary operating procedures

2010-13 Raphael Auer: Consumer Heterogeneity and the Impact of Trade Liberalization: How Representative is the Representative Agent Framework?

2010-14 Tommaso Mancini Griffoli and Angelo Ranaldo: Limits to arbitrage during the crisis: funding liquidity constraints and covered interest parity

2010-15 Jean-Marc Natal: Monetary Policy Response to Oil Price Shocks

2010-16 Kathrin Degen and Andreas M. Fischer: Immigration and Swiss House Prices

2010-17 Andreas M. Fischer: Immigration and large banknotes

2010-18 Raphael Auer: Are Imports from Rich Nations Deskilling Emerging Economies? Human Capital and the Dynamic Effects of Trade 
2010-19 Jean-Pierre Danthine and John B. Donaldson: Executive Compensation: A General Equilibrium Perspective

2011-1 Thorsten Beck and Martin Brown: Which Households Use Banks? Evidence from the Transition Economies

2011-2 Martin Brown, Karolin Kirschenmann and Steven Ongena: Foreign Currency Loans Demand or Supply Driven?

2011-3 Victoria Galsband and Thomas Nitschka: Foreign currency returns and systematic risks

2011-4 Francis Breedon and Angelo Ranaldo: Intraday patterns in FX returns and order flow

2011-5 Basil Guggenheim, Sébastien Kraenzlin and Silvio Schumacher: Exploring an uncharted market: Evidence on the unsecured Swiss franc money market

2011-6 Pamela Hall: Is there any evidence of a Greenspan put?

2011-7 Daniel Kaufmann and Sarah Lein: Sectoral Inflation Dynamics, Idiosyncratic Shocks and Monetary Policy

2011-8 Iva Cecchin: Mortgage Rate Pass-Through in Switzerland

2011-9 Raphael A. Auer, Kathrin Degen and Andreas M. Fischer: Low-Wage Import Competition, Inflationary Pressure, and Industry Dynamics in Europe

2011-10 Raphael A. Auer and Philip Sauré: Spatial Competition in Quality, Demand-Induced Innovation, and Schumpeterian Growth

2011-11 Massimiliano Caporin , Angelo Ranaldo and Paolo Santucci de Magistris: On the Predictability of Stock Prices: a Case for High and Low Prices

2011-12 Jürg Mägerle and Thomas Nellen: Interoperability between central counterparties

2011-13 Sylvia Kaufmann: K-state switching models with endogenous transition distributions

2011-14 Sébastien Kraenzlin and Benedikt von Scarpatetti: Bargaining Power in the Repo Market

2012-01 Raphael A. Auer: Exchange Rate Pass-Through, Domestic Competition, and Inflation: Evidence from the 2005/08 Revaluation of the Renminbi

2012-02 Signe Krogstrup, Samuel Reynard and Barbara Sutter: Liquidity Effects of Quantitative Easing on Long-Term Interest Rates 
2012-03 Matteo Bonato, Massimiliano Caporin and Angelo Ranaldo: Risk spillovers in international equity portfolios 
Swiss National Bank Working Papers are also available at www.snb.ch, section Publications/Research Subscriptions or individual issues can be ordered at Swiss National Bank, Fraumünsterstrasse 8, CH-8022 Zurich, fax+41 4463181 14, E-mail library@snb.ch 